\title{
A Case Report of an Invasive Scalp Actinomycosis
}

\section{Youssouf Sogoba', Jean Paul Dembele², Boubacar Sogoba', Moussa Diallo', Seybou Hassane Diallo3, Oumar Coulibaly4, Quenum Kisito5, Oumar Diallo, Drissa Kanikomo', Youssoufa Maiga ${ }^{3}$}

\author{
${ }^{1}$ Department of Neurosurgery, Hôpital Gabriel Touré, Bamako, Mali \\ ${ }^{2}$ Department of Infectious Diseases, Hôpital du Point G, Bamako, Mali \\ ${ }^{3}$ Department of Neurologie, Hôpital Gabriel Touré, Bamako, Mali \\ ${ }^{4}$ Department of Neurosurgery, Hôpital du Mali, Bamako, Mali \\ ${ }^{5}$ Department of Neurosurgery, University Hospital of Parakou, Parakou, Benin \\ Email: sogobayoussouf@yahoo.fr
}

How to cite this paper: Sogoba, Y., Dembele, J.P., Sogoba, B., Diallo, M., Diallo, S.H., Coulibaly, O., Kisito, Q., Diallo, O., Kanikomo, D. and Maiga, Y. (2021) A Case Report of an Invasive Scalp Actinomycosis. Case Reports in Clinical Medicine, 10, 34-38. https://doi.org/10.4236/crcm.2021.102005

Received: January 16, 2021

Accepted: February 21, 2021

Published: February 24, 2021

Copyright (c) 2021 by author(s) and Scientific Research Publishing Inc. This work is licensed under the Creative Commons Attribution International License (CC BY 4.0)

http://creativecommons.org/licenses/by/4.0/

\begin{abstract}
Background: Actinomycosis is a bacterial infection characterized by a chronic, suppurative and granulomatous process. The causative organism was identified in 1891 as Actinomycosis israelii. The disease is usually caused by the introduction of the bacteria through minor wound. Actinomycosis was classified by Cope into 3 different forms: cervicofacial (50\%), pulmonothoracic (30\%) and abdominopelvic (20\%). Actinomycosis is an insidious disease but occasionally the clinical course can be more aggressive, involving underline tissue and organs. Involvement of scalp by actinomycosis is rare causing diagnostic dilemma and could be mistaken for different pathologies, such as tuberculosis or carcinoma. The most common clinical findings are local tumefaction with abscesses and sinuses draining pus that contains the granule of the causative organism. CT scan and MRI are aspecific for diagnosis, but they can help in defining the localization and the extension of the lesion. The certain diagnostic is based on cytology and/or biopsy. Case: A 24 year-old-man was admitted to our neurosurgical department with a 16-month history of multiple scalp ulcerated lesions and swelling of the head. He was complaining of headache. Physical examination revealed multiple scalp subcutaneous nodules and ulcerated lesions with swelling of the head. Our examination of the oral cavity revealed a poor oral hygiene condition with multiple caries. The CT scan revealed multiple scalp subcutaneous masses with chronic inflammatory changes of the skull. Routine laboratory test was normal. Surgical biopsy was performed and the histological result was compatible with actinomycosis. After histological confirmation, parenteral Penicillin 20 million units daily were given for 4 weeks. Clinical improvement was observed after completing a
\end{abstract}


4-week regimen of intravenous antibiotics. Conclusion: Involvement of scalp by actinomycosis could be mistaken for different pathologies, such as tuberculosis or carcinoma. This emphasizes the importance of biopsy for histological confirmation of the disease.

\section{Keywords}

Actinomycosis, Bacterial Infection, Computed Tomography

\section{Introduction}

Actinomycosis is a bacterial infection characterized by a chronic, suppurative and granulomatous process [1]. The causative organism was identified in 1891 as Actinomycosis israelii [2]. The disease is usually caused by the introduction of the bacteria through minor wound. Actinomycosis was classified by Cope into 3 different forms: cervicofacial (50\%), pulmonothoracic (30\%) and abdominopelvic (20\%) [3]. It is an insidious disease but occasionally the clinical course can be more aggressive, involving underline tissue and organs. Involvement of scalp by actinomycosis is rare causing diagnostic dilemma and could be mistaken for different pathologies, such as tuberculosis or carcinoma [4]. The most common clinical findings are local tumefaction with abscesses and sinuses draining pus that contains the granule of the causative organism. CT scan and MRI are aspecific for diagnosis, but they can help in defining the localization and the extension of the lesion [5]. The certain diagnostic is based on cytology and/or biopsy [6]. In this paper, the authors report a rare case of an invasive scalp actinomycosis that was successfully treated with prolonged intravenous and oral antibiotics.

\section{Case Report}

A 24-year-old-man was admitted to our neurosurgical department with a 16-month history of multiple scalp ulcerated lesions and swelling of the head. The patient had a history of headache but no fever. On admission, his body temperature was $37.5^{\circ} \mathrm{C}$, blood pressure $110 / 70 \mathrm{mmHg}$, heart rate 65 b.p.m. The consciousness was correct with a Glasgow Coma Scale 15 and no evidence of focal neurological deficit. Physical examination revealed multiple scalp subcutaneous nodules and ulcerated lesions with swelling of the head (Figure 1). Our examination of the oral cavity revealed a poor oral hygiene condition with multiple caries. The CT scan (Figure 2) revealed multiple scalp subcutaneous masses with chronic inflammatory changes of the skull. Routine laboratory test was normal particularly white blood cell count, C-reactive protein level, Intradermo-reaction with tuberculin and HIV test. Surgical biopsy was performed and the histological result was compatible with actinomycosis. After histological confirmation, parenteral Penicillin 20 million units daily were given for 4 weeks. Clinical improvement was observed after completing a 4-week regimen of intravenous 


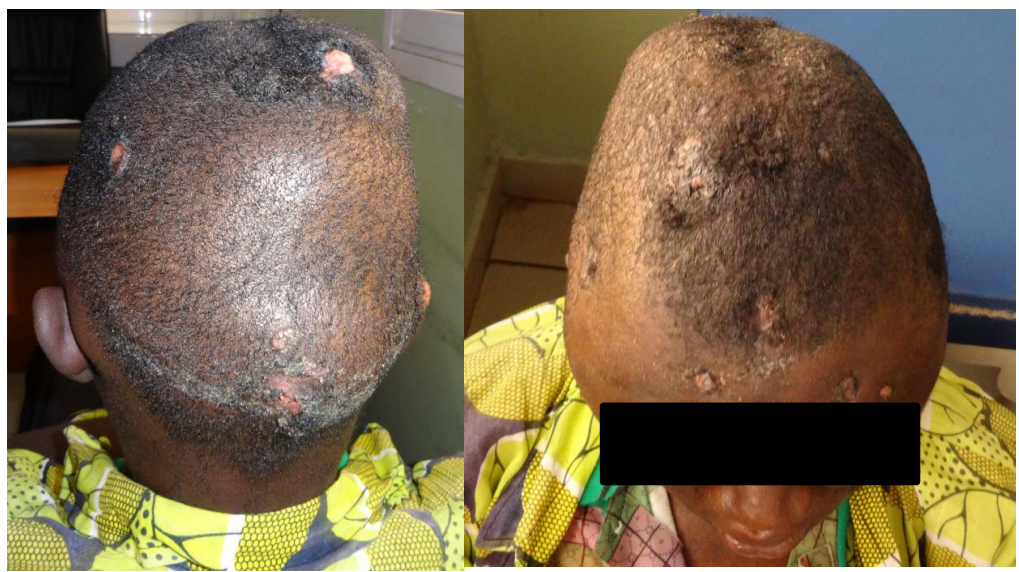

Figure 1. Clinical photograph showing multiple scalp subcutaneous nodules and ulcerated lesions with swelling of the head.

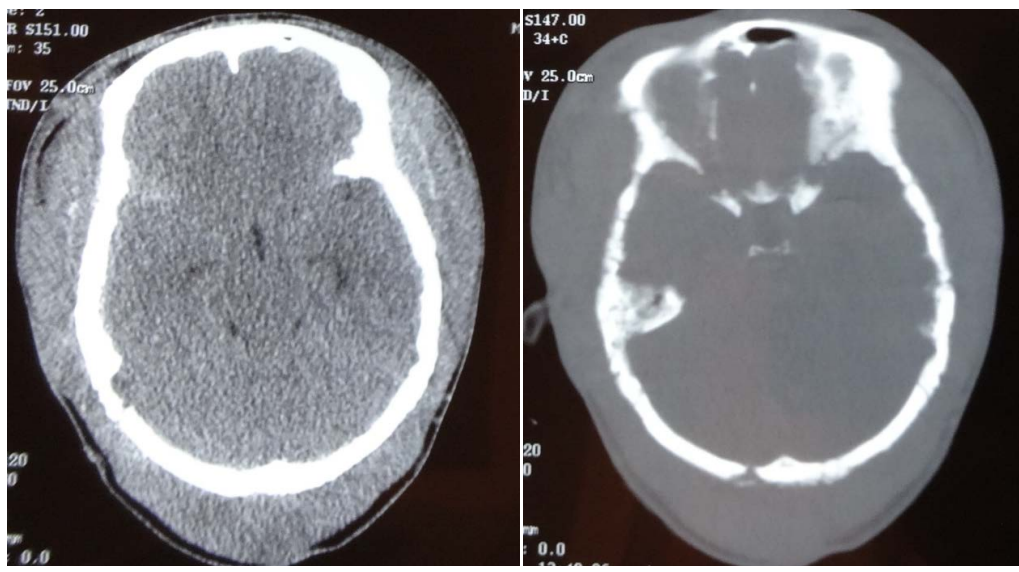

Figure 2. CT scan showing scalp subcutaneous masses with chronic inflammatory changes of the skull.

antibiotics. The patient was referred to the dentist and oral amoxicillin was given for an additional treatment.

\section{Discussion}

We described a rare case involving a 24-year-old man who developed an invasive scalp actinomycosis. The first description of actinomycosis dates back to 1878 [7]. The causative agent is an anaerobic, Gram-positive bacterium often found as a saprophytic germ in the oral cavity and the gastrointestinal tract. This emphasizes the importance to investigate if the patient has any risk factors to suspect actinomycosis such as poor oral hygiene or immunosuppression [8]. In our case, HIV test was negative but the patient had a poor oral hygiene. Actinomyces is particularly known for its ability to cross tissue planes leading to involvement of contiguous tissue and distant organs [9]. More than 30 species of Actinomyces have been described and the most implicated in human actinomycosis are: $A c$ tinomyces israelii, Actinomyces naeslundii, Actinomyces viscosus, Actinomyces odontolyticus and Actinomyces meyeri. The disease usually progresses chroni- 
cally [10] [11]. Actinomycosis is rare and has been sporadically reported in the literature. The most common forms are cervicofacial in 50\%, thoracic in 30\% and abdominal in $20 \%$. Cranial involvement of actinomycosis is rare and occurs in less than $4 \%$ of cases [12]. Involvement of scalp by actinomycosis may cause diagnosis dilemma and could be mistaken for different pathologies, such as tuberculosis or carcinoma [4]. Cases of scalp actinomycosis have been sporadically reported in the literature [10]-[16]. Very often, the disease is localized on a part of the scalp. In our case, actinomycosis was more aggressive involving the entire scalp. The certain diagnosis is based on cytology and/or biopsy [6]. In our case, surgical excision was performed to remove as much as possible the granuloma and to allow histopathological examination. The main therapeutic treatment is administration of antibiotics. Actinomyces is extremely sensitive to penicillin G. Other antibiotics like Erythromycin and tetracycline can be used in patients allergic to penicillin [17]. In the literature, successful treatment was also achieved by using other antibiotics like streptomycine [13], cotrimoxazole [14] and itraconazole [10]. The antibiotic must be administered in high dose over prolonged period because of the tendency of the disease to recur [18]. We used parenteral Penicillin 20 million units daily during 4 weeks followed by oral amoxicillin for additional treatment.

\section{Conclusion}

Involvement of scalp by actinomycosis could be mistaken for different pathologies, such as tuberculosis or carcinoma. This emphasizes the importance of biopsy for histological confirmation of the disease.

\section{Conflicts of Interest}

The authors declare no conflicts of interest regarding the publication of this paper.

\section{References}

[1] Nelson, E.G. and Tybor, A.G. (1992) Actinomycosis of the Larynx. Ear, Nose and Throat Journal, 71, 356-358. https://doi.org/10.1177\%2F014556139207100805

[2] Mabeza, G.F. and Macfarlane, J. (2003) Pulmonary Actinomycosis. European Respiratory Journal, 21, 545-551. https://doi.org/10.1183/09031936.03.00089103

[3] Cevera, J.J., Butehorn III, H.F., Shapiro, J. and Setzen, G. (2003) Actinomycosis Abscess of the Thyroid Gland. Laryngoscope, 113, 2108-2111. https://doi.org/10.1097/00005537-200312000-00009

[4] Atay, Y.A., Altintas, A., Tuncer, I. and Cennet, A. (2005) Ovarian Actinomycosis Mimicking Malignancy. European Journal of Gynaecological Oncology, 26, 663-664.

[5] Goldberg, M.H. (2003) Diagnosis and Treatment of Cervicofacial Actinomycosis. Oral and Maxillofacial Surgery Clinics of North America, 15, 51-58. https://doi.org/10.1016/S1042-3699(02)00074-2

[6] Pontifex, A.H. and Roberts, F.J. (1985) Fine Needle Aspiration Biopsy Cytology in the Diagnosis of Inflammatory Lesions. Journal Acta Cytologica, 29, 979-982. 
[7] Bennhoff, D.F. (1984) Actinomycosis Diagnostic and Therapeutic Considerations and Review of 32 Cases. Laryngoscope, 94, 1198-1217. https://doi.org/10.1288/00005537-198409000-00013

[8] Brook, I. (2008) Actinomycosis: Diagnosis and Management. Southern Medical Journal, 101, 1019-1023.

[9] Clancy, U., Ronayne, A., Prentice, M.B. and Jackson, A. (2015), Actinomyces meyeri Brain Abscess Following Dental Extraction. BMJ Case Reports, 2015, Article ID: bcr2014207548. http://dx.doi.org/10.1136/bcr-2014-207548

[10] Beeram, V., Challa, S. and Vannemreddy, P. (2008) Cerebral Mycetoma with Cranial Osteomyelitis. Journal of Neurosurgery: Pediatrics PED, 1, 493-495. https://doi.org/10.3171/PED/2008/1/6/493

[11] Soto-Mendoza, N. and Bonifaz, A. (2000) Head Actinomycetoma with a Double Aetiology, Caused by Nocardia brasiliensis and N. asteroides. British Journal of Dermatology, 143, 192-194. https://doi.org/10.1046/j.1365-2133.2000.03615.x

[12] Gumaa, S.A., Mahgoub, E.S. and El Sid, M.A. (1986) Mycetoma of the Head and Neck. The American Journal of Tropical Medicine and Hygiene, 35, 594-600. https://doi.org/10.4269/ajtmh.1986.35.594

[13] Shanbhag, N.U., Karandikar, S. and Deshmukkh, P.A. (2010) Disseminated Orbital Actinomycetoma: A Case Report. Indian Journal of Ophthalmology, 58, 60-63. https://doi.org/10.4103/0301-4738.58474

[14] Verma, S., Nayak, S., Pasale, R., Kittner, T. and Wollina, U. (2008) Late Complication after Tropic Storm Accident: Subcutaneous and Intracranial Actinomycetoma. International Wound Journal, 5, 655-659. https://doi.org/10.1111/j.1742-481X.2008.00456.x

[15] Kumar, G.S., Chacko, G., Mathews, M.S. and Mathew, J.M. (2005) Intracranial Actinomadura Granuloma. Neurology India, 53, 368-370.

https://doi.org/10.4103/0028-3886.16952

[16] Arbab, M.A., Idris, M.N., Sokrab, T.E., Saeed, E.S., Ali, G.M., Tariq, M.Y., et al. (1998) Clinical Presentation and CAT Scan Findings in Mycetoma of the Head. East African Medical Journal, 75, 246-248.

[17] Vorasubin, N., Wu, A.W., Day, C. and Suh, J.D. (2013) Invasive Sinonasal Actinomycosis: Case Report and Literature Review. Laryngoscope, 123, 334-338. https://doi.org/10.1002/lary.23477

[18] Park, J.K., Lee, H.K., Ha, H.K., Choi, H.Y. and Choi, C.G. (2003) Cervicofacial Actinomycosis: CT and MR Imaging Findings in Seven Patients. American Journal of Neuroradiology, 24, 331-335. 